\title{
Effect modification by GST and TNF- $\alpha$ polymorphisms in the association between air pollution and lung function in asthmatic children
}

\author{
Eliane Silva ${ }^{1}$, Jamila Perini ${ }^{2}$, Ismael Silveira ${ }^{3}$, Lucas Lopes ${ }^{4}$, Taísa Cortes ${ }^{5}$, Beatriz \\ Oliveira $^{6}$, and Washington Junger ${ }^{1}$ \\ ${ }^{1}$ Rio de Janeiro State University \\ ${ }^{2}$ State University Centre of the West Zone \\ ${ }^{3}$ Federal University of Bahia \\ ${ }^{4}$ Sergio Arouca National School of Public Health \\ ${ }^{5}$ Institute of Social Medicine \\ ${ }^{6}$ Oswaldo Cruz Foundation
}

July 10, 2021

\begin{abstract}
Background: Air pollutants induce the increase of inflammatory components in the lungs and the decrease in pulmonary function. Genetic polymorphisms may modify the inflammatory and immunological response to the inhalation of those pollutants. Objective: To investigate effect modification by GST and TNF- $\alpha$ polymorphisms in the association between particulate matter (PM10) and lung function. Methods: This is a cross-sectional epidemiological study with 112 asthmatic children aged 6 to 14 years old. GSTM1, GSTT1, GSTP1, and TNF- $\alpha$ polymorphisms were genotyped using the polymerase chain reaction (PCR) technique. Spirometry tests were conducted. We tested associations using generalized linear models, adjusting for confounding variables. The effect modification of the genetic polymorphisms was assessed, including the genotypes and pollutants. Results: In carriers of the TNF- $\alpha-308$ GA or AA genotypes, we found a reduction of $11.5 \%$ (95\% CI: -19.08, -3.30) in FEV1 in the current exposure to PM10 and a reduction of $10.46 \%$ (95\% CI: -14.91, -5.77) for the 5-day cumulative exposure. The TNF- $\alpha$ - 1031 TT genotype was associated with a decline in FEV1 and FEF25-75\% for the cumulative exposure to PM10. The GSTP1 wild-type genotype was associated with a decrease in FEF25-75\% of 23.45\% (95\% CI; -30.6, -15.56) and in FEV1 of $13 \%$ (95\% CI; - 15.21 , -10.74). We found that among GSTT1 null children, the cumulative exposure to PM10 was also associated with a reduction in FEV1, FVC, and FEF25-75\%. Conclusion: Genetic polymorphism in GST and TNF- $\alpha$ may modify the association between particulate matter and pulmonary function in asthmatic children and adolescents.
\end{abstract}

\section{INTRODUCTION}

Asthma is a chronic inflammatory disease that affects approximately 339 million people worldwide, representing the main chronic disease among children ${ }^{1}$. The pathogenesis of asthma can involve complex relationships between environmental, behavioral, and genetic factors ${ }^{2}$. Among the environmental factors, consistent evidence indicates that exposure to gaseous and particulate pollutants may induce or aggravate asthma ${ }^{3}$. Although the mechanisms underlying the relationship between air pollution and asthma are not fully understood, potential physiological pathways may include induction of airway inflammation and oxidative stress, failures in bronchial epithelial barrier function, and alterations in the immune responses ${ }^{4,5,6}$. 
These mechanisms can contribute to bronchial hyperreactivity, pulmonary remodeling, and reduced lung function.

Previous studies have shown that the effects of air pollution on respiratory outcomes may vary according to age, gender, ethnicity, and socioeconomic status ${ }^{3,7}$. Genetic and epigenetic mechanisms may also contribute to susceptibility to the respiratory effects of air pollution by association with the biological response to air pollutants, such as oxidative stress and inflammatory pathways.

Among the several candidate genes related to antioxidative stress systems, particular attention has been paid to the genes of glutathione S-transferases $(\mathrm{GST})^{8,9}$. GST genes encode for phase II xenobiotic-metabolizing enzymes that participate in cellular defense against chemically induced toxicity and oxidative stress ${ }^{10}$. It has been hypothesized that GST polymorphisms that alter GST function may lead to increased or decreased susceptibility to toxic environmental agents.

Polymorphisms of genes encoding tumor necrosis factor-alpha $(T N F-\alpha)$ have also been investigated as potential modifiers of the effects of air pollution on asthma outcomes ${ }^{11}$. TNF $-\alpha$ is a pro-inflammatory cytokine that plays a critical role in host defense against infection. The single nucleotide polymorphism (SNP) $T N \Phi$ $a-308 \Gamma>A$ has been associated with higher production of $T N F-\alpha$ and the subsequent amplification of the inflammatory response to oxidizing agents, which may contribute to susceptibility to induction and exacerbation of asthma ${ }^{12,13}$.

Although previous reviews have reported that GST and TNF $-\alpha$ polymorphisms may interplay with the effects of air pollution on respiratory outcomes, the results are highly heterogeneous across studies $8,9,11,14$. In addition, few studies have investigated genetic susceptibility to the effects of particulate matter on lung function.

In this study, we investigate effect modification by the polymorphism of GSTM1, GSTT1, GSTP1 and $T N \Phi-a$ genes in the association between particulate matter $\left(\mathrm{PM}_{10}\right)$ and pulmonary function in asthmatic children and adolescents.

\section{MATERIALS AND METHODS}

This cross-sectional study was carried out from November 2015 to December 2016. The initial sample included 133 children and adolescents aged between 6 and 14 years old, with a medical diagnosis of asthma, residing in the city of Rio de Janeiro. Participants were recruited from routine consultations at outpatient clinics that provide specialized asthma care at two municipal health centers. Children and adolescents with severe asthma and other pulmonary pathologies were excluded from the study. After the guardians signed the consent form, study participants underwent spirometry and anthropometric tests and had oral cells collected. The final study sample included 112 participants.

\section{Pulmonary function}

Spirometry was performed with the Kokoß portable spirometer. The test was carried out according to the criteria established by the American Thoracic Society $(1995)^{15}$. Spirometric parameters included: forced expiratory volume in the first second $\left(\mathrm{FEV}_{1}\right)$, forced vital capacity $(\mathrm{FVC})$, and forced expiratory flow between $25 \%$ and $75 \%$ of vital capacity $\left(\mathrm{FEF}_{25-75 \%}\right)$. The results were expressed as a percentage of the predicted value.

\section{Covariate data}

Covariate data were collected through a structured questionnaire completed by the parent or guardian of each child. The questionnaire included information on sex, age, presence of asthma symptoms in the last four weeks, family income, maternal education, passive smoking, and use of corticosteroids. 


\section{Exposure assessment}

Daily concentrations of particulate matter $\left(\mathrm{PM}_{10}\right)$ were obtained from the Municipal Environment Department of Rio de Janeiro (SMAC). Exposure was calculated as the average concentration of the monitoring sites located closest to the participants' residence. The mean daily concentrations of $\mathrm{PM}_{10}$ were calculated for the same day of the spirometry test (thus representing current exposure or lag 0 exposure) and up to 5 days before the measurement of pulmonary function (5-day lagged exposures).

\section{Genotyping}

Genomic DNA was obtained from exfoliative cells by swabbing the oral mucosa. For DNA extraction, we used the Invisorb Spin Swabß kit (Invitrogen). The genotyping of $T N F \alpha-1031 T>C$ (rs1799964), -308G $>A$ (rs1800629) and GSTP1(Ile105Val - rs1695) polymorphisms was performed using the polymerase chain reaction $(\mathrm{PCR}$ ) technique in real time with the aid of TaqMan probes (Applied Biosystems, Foster City, CA, USA). The genotypes of GSTM1 and GSTT1 were characterized using the multiplex PCR technique ${ }^{16}$. The absence of PCR products for GSTM1 or GSTT1 in the presence of bands of the internal control CYP1A1 was indicative of the null genotype. The subjects were classified as either present $(+)$, when at least one specimen of the gene was detected, or null (-), when they showed absence of the gene.

\section{Statistical analysis}

Linear regression models and polynomial distributed lag models (PDLM) were used to assess the association between exposure to particulate matter and the logarithm of pulmonary function. Effect estimates are presented as the percentage change in the parameters of pulmonary function for each increase of $10 \mu \mathrm{g} / \mathrm{m} \mathrm{in}$ $\mathrm{PM}_{10}$ exposure on the day of the spirometry test and up to 5 days lag.

We used causal directed acyclic graphs (DAG) to select a sufficient adjustment set of variables that would allow the identification of the total and cumulative effect of $\mathrm{PM}_{10}$ on pulmonary function. Potential confounders included common causes of both exposure and outcome and predictors of lung function. The sufficient adjustment set was identified using the DAGitty application ${ }^{17}$ and included the variables sex, age, socioeconomic status, height, and ambient temperature (at 5-day lag). We used the same adjustment set of covariates for all models, and maternal education was used as a proxy for family socioeconomic status (Figure 1).

The Hardy-Weinberg Equilibrium (HWE) was calculated for all polymorphisms and evaluated using the Chi-square method. Effect modification was assessed by stratified analyses according to genotype groups.

The GST polymorphisms were encoded as GSTP1 Ile105 wild type (AA or Ile/Ile - dominant homozygote) or Val105 variant (AG or Ile/Val - heterozygote or GG or Val/Val - homozygote); GSTM1 and GSTT1 were genotyped as present $+/+$ (absence of polymorphism) or null -/- (presence of polymorphism). The TNF $-\alpha$ SNP was dichotomized into two groups based on the absence or presence of the polymorphic allele. TNF- $\alpha-$ 1031 T-C into TT (Wild type homozygous) versus TC (heterozygous variant) or CC (homozygous variant) and TN $\Phi$ - $a$ - 308G-A into GG (Wild type homozygous) versus GA (heterozygous variant) or AA (homozygous variant). All the analyses were performed using the $\mathrm{R}$ software (The $\mathrm{R}$ Project for Statistical Computing) and the packages $\mathrm{X}, \mathrm{Y}$ and $\mathrm{Z}$.

\section{RESULTS}

A total of 133 children and teenagers with a medical diagnosis of asthma were recruited. Of these, 21 were excluded from the analysis because they did not undergo the spirometric test according to the ATS standardization (1995) or their home address was not georeferenced (Figure 2). Of the 112 children and adolescents included in this study, $67.9 \%$ had a monthly family income lower than or equal to two minimum 
wages, and $32 \%$ were exposed to secondhand tobacco smoke. The average age of the population was 9 years old. Approximately $32 \%$ of the sample reported asthma symptoms in the last four weeks, and $83.9 \%$ were using regular inhaled corticosteroids for asthma treatment (Table 1).

All the studied polymorphisms were in Hardy-Weinberg Equilibrium. The distribution of TN $T-a-308$ and $T N \Phi-a-1031$ homozygous variant genotypes was $0.9 \%$ and $11.6 \%$, and the distribution of GSTP1, GSTM1 and GSTT1 antioxidant genes was $16.1 \%, 35.7 \%$ and $30.4 \%$, respectively (Table 1).

During the study period, the annual average concentrations of $\mathrm{PM}_{10}$ exceed the guideline value of $20 \mu \mathrm{g} / \mathrm{m}^{3}$, with an average of $38.6 \mu \mathrm{g} / \mathrm{m}^{3}$, and exceeded the reference limit of $50 \mu \mathrm{g} / \mathrm{m}^{3}$ for daily average in $16.3 \%$ of the days (65 days).

\section{Associations between $\mathrm{PM}_{10}$ and pulmonary function according to genotype}

Among children and adolescents with $T N \Phi-a-308 \mathrm{GA}$ or AA genotypes, we found a reduction of $11.5 \%$ (95\% CI: $-19.08,-3.30)$ in $\mathrm{FEV}_{1}$ for each increase of $10 \mu \mathrm{g} / \mathrm{m}^{3}$ in the current exposure to $\mathrm{PM}_{10}$ and a reduction of $10.46 \%$ (95\% CI: $-14.91,-5.77)$ for the 5-day cumulative exposure. Among those with the TN $\Phi$ - $a$-308 GG genotype, the reduction in $\mathrm{FEV}_{1}$ was lower both for current $(-1.84 ; 95 \% \mathrm{CI}$ : $-4.75,1.17)$ and cumulative exposure (-5.47; 95\% CI: -6.80, -4.12) (Figure 3; E-table 1).

Among participants with the TN $\Phi-a-1031$ TT genotype, the cumulative exposure to $\mathrm{PM}_{10}$ was associated with a higher decline in $\mathrm{FEV}_{1}(-7.13 ; 95 \% \mathrm{CI}:-9.25,-4.95)$ compared to those with $T N \Phi-a-1031$ TC or CC genotypes $(-4.59 ; 95 \%$ CI: $-6.50,-2.64)$. In these subgroups, the same pattern was observed for the $\mathrm{FEF}_{25-75 \%}$ parameter (Figure 3; E-table 1).

The greatest deficit in pulmonary function associated with $\mathrm{PM}_{10}$ exposure was found among children with the GSTP1 Ile/Ile genotype. For this group, cumulative exposure to $\mathrm{PM}_{10}$ was associated with a decline in $\mathrm{FEF}_{25-75 \%}$ of $23.45 \%$ (95\% CI; -30.6, -15.56) and a reduction of $13 \%$ in $\mathrm{FEV}_{1}$ (95\% CI; -15.21, -10.74) (Figure 3,5; E-table 2).

We found that among GSTT1 null children, cumulative exposure to $\mathrm{PM}_{10}$ was also associated with a greater reduction in $\mathrm{FEV}_{1}, \mathrm{FVC}$, and $\mathrm{FEF}_{25-75 \%}$ compared to the GSTT1 non-null genotype (Figure 3-5) (E-table 2).

As for the GSTM1 genotypes, no differences were found in the associations between $\mathrm{PM}_{10}$ exposure and pulmonary function parameters.

\section{DISCUSSION}

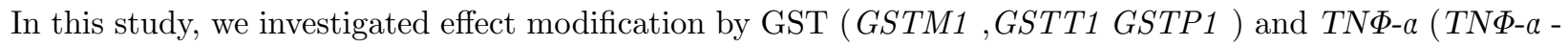
308 and $T N \Phi-\alpha-1031 \mathrm{SNP}$ ) gene polymorphisms in the association between particulate matter and pulmonary function in asthmatic children and adolescents. Our results suggested that carriers of the GSTT1 null allele, as well as the GSTP1 lle/lle genotype, had a greater reduction in pulmonary function associated with exposure to $\mathrm{PM}_{10}$. We also found suggestive evidence for effect modification by $T N \Phi-a-308$ and TN $T$ - $a$ 1031 polymorphisms.

We found an inverse association between $\mathrm{PM}_{10}$ exposure and pulmonary function in most of the subgroup analyses. These results are similar to previous findings, which indicate that acute exposure to air pollutants is associated with a decline in lung function in children ${ }^{3}$. Identifying genetic and environmental factors that influence lung development in childhood allows the adoption of intervention measures that preserve the lungs. This is particularly important since childhood lung function is a predictor of lung integrity in adulthood and correlates with functional deficits throughout life ${ }^{18,19}$. 
There is growing evidence that oxidative stress mediates the effects of air pollution on respiratory outcomes ${ }^{6}$. GSTs enzymes are generally considered an essential component in the protection against the by-products of oxidative stress ${ }^{20}$. It has been shown that some GST genes polymorphisms may affect the functioning of the encoded enzymes. The GSTM1 and GSTT1 null genotypes are related to a complete absence of the corresponding proteins, while the GSTP1 lle/Val and GSTP1 Val/Val polymorphisms are often associated with reduced enzymatic activity ${ }^{20,21}$. Such polymorphisms are believed to contribute to susceptibility to the adverse effects of air pollution and individual differences in respiratory outcomes.

In this study, children with the Ile/Ile wild genotypes of GSTP1 showed a greater reduction in $\mathrm{FEV}_{1}$, FVC, and $\mathrm{FEF}_{25-75 \%}$, compared to the variant Ile/Val or Val/Val genotypes. This result contrasts with some previous findings, which suggest that the GSTP1 Ile/Val or Val/Val genotypes are associated with increased pollutant effects on respiratory parameters among children ${ }^{22,23,24}$ and adults ${ }^{25}$. Although the allelic variants of GSTP1 Val decrease the enzymatic activity of glutathione, their presence has also been associated with lower risk of being susceptible to the respiratory effects of air pollutants ${ }^{14,26,27}$, including a lower decline in lung function 28,29 .

We found that carriers of the GSTT1 null allele had a greater reduction in $\mathrm{FEV}_{1}, \mathrm{FVC}$, and $\mathrm{FEF}_{25-75 \%}$ as the exposure to $\mathrm{PM}_{10}$ increased. Few studies have investigated the role of the GSTT1 genotype in the relationship between exposure to $\mathrm{PM}_{10}$ and lung function. Zhang et al. (2016) found that adults with the GSTT1 null showed reduced $\mathrm{FEV}_{1}$ when exposed to diesel combustion particles ${ }^{30}$. In contrast, Hong et al. (2007) reported no differences in the associations between $\mathrm{PM}_{2.5}$ exposure and peak expiratory flow rate among GSTT1 genotypes in schoolchildren ${ }^{31}$. However, a recent meta-analysis found that the null genotype was associated with increased risk of childhood asthma ${ }^{32}$. Another study reported that the GSTT1 null was related to increased inflammation biomarkers among atopic individuals exposed to diesel combustion ${ }^{33}$.

We found no evidence of effect modification by the GSTM1 genotype on the association between $\mathrm{PM}_{10}$ and pulmonary function. Previous reviews reported no consistent evidence regarding the role of GSTM1 polymorphisms ${ }^{9}$ : while some studies report a higher deficit in lung function associated with air pollution among individuals with the GSTM1 null ${ }^{14,28,34,35}$, others do not ${ }^{21,31}$. Moreover, other studies indicate that GSTM1 may confer greater susceptibility to the respiratory effects of air pollution only in combination with other variant genotypes ${ }^{9}$.

Another related mechanism mediating the effects of air pollution on respiratory outcomes is the induction of a persistent inflammatory state. In the present study, asthmatic children and adolescents withTN $\Phi-a$ $-308 \mathrm{GA}$ or AA variant genotypes had a greater reduction in $\mathrm{FEV}_{1}$ as the exposure to $\mathrm{PM}_{10}$ increased. The presence of the variant A allele in the $T N \Phi-\alpha-308$ SNP can increase the activation of transcription factors by six to seven times, changing the expression of the gene and amplifying the intensity of the inflammatory response to oxidants ${ }^{12,13}$. Therefore, it is plausible to state that the TN $\Phi$ - $a-308$ polymorphism contributes to the reduction of lung function in asthmatics. A higher deficit in pulmonary parameters with an increased exposure to air pollution has also been observed in other studies with different pollutants, including $\mathrm{SO}_{2}$ and $\mathrm{NO}^{36}$ and ozone ${ }^{37}$. In contrast, Li et al. (2006) found that children with the $T N \Phi$ - $a$ - 308 GG genotype had lower risk for asthma and wheezing at low levels of ozone exposure $\left(\mathrm{O}_{3}\right)$, but this protective effect was reduced at higher $\mathrm{O}_{3}$ concentrations and even more so in the combination of the variant alleles of the GSTM1 and GSTP1 genes $^{38}$. In other studies, the effect modification by $T N \Phi-a-308$ genotypes was observed only in conjunction with the variant genotype of the GSTP1 gene $^{39}$.

The conflicting results found in the literature regarding the role of $G S T$ and $T N \Phi$ - $a$ genes polymorphisms reinforce the need for further studies. In addition to methodological differences across studies, the heterogeneity of the results could be explained by differences among populations regarding the structure and distribution of effect modifiers, including factors related to air pollution, lung function, and gene expression. It is also worth mentioning that different adjustments for confounding can generate different conclusions regarding causal effect modification or interaction ${ }^{40}$. In the present study, we used causal diagrams to guide the assessment of effect modification, possibly minimizing confounding and collider bias on the estimation of total and cumulative effects. 
Our results must be interpreted in light of some limitations. Our reduced sample size might have led to low statistical power, which imposes limitations on the interpretation of null findings and observed differences in pollutant effects across genotypes. In addition, our sample size prevents us from investigating effect modification by possible combinations of polymorphisms and modulation with other environmental factors. Previous findings suggest that complex patterns between genes and pollutants may characterize genetic susceptibility to the respiratory effects of air pollution ${ }^{9}$.

Furthermore, we used data from the nearest background stations to assign a $\mathrm{PM}_{10}$ exposure to each subject. Although this could have reduced measurement error, we cannot rule out the possibility of exposure misclassification.

In conclusion, we found suggestive evidence that genetic variants in $G S T$ and $T N \Phi-a$ may modify the association between particulate matter and pulmonary function in asthmatic children and adolescents. Further and larger studies are needed to provide more conclusive evidence regarding the role of GST and TN $T$ - $a$ polymorphisms in the relationship between air pollution and lung function.

Identifying susceptible populations to the respiratory effects of air pollution is essential to the development and implementation of public health policies. Understanding the mechanisms underlying genetic vulnerability is also critical to improve the clinical treatment of asthma and other respiratory diseases.

\section{REFERENCES}

1. Global, regional, and national incidence, prevalence, and years lived with disability for 328 diseases and injuries for 195 countries, 1990-2016: a systematic analysis for the Global Burden of Disease Study 2016. Lancet 2017; 390: 1211-59.

2. Lemanske RF, Busse WW. Asthma: Clinical expression and molecular mechanisms. J Allergy Clin Immunol 2010;125(2):S95-S102.

3. Tiotiu AI, Novakova P, Nedeva D, Chong-Neto HJ, Novakova S, Steiropoulos P, Kowal K. Impact of Air Pollution on Asthma Outcomes. Int J Environ Res Public Health 2020 Sep; 17(17): 6212.

4. Huang S-K, Zhang Q, Qiu Z, Chung KF. Mechanistic impact of outdoor air pollution on asthma and allergic diseases. J Thorac Dis 2015;7(1):11.

5. Huff RD, Carlsten C, Hirota JA. An update on immunologic mechanisms in the respiratory mucosa in response to air pollutants. J Allergy Clin Immunol 2019;143(6):1989-2001.

6. Thimmulappa RK, Chattopadhyay I, Rajasekaran S. Oxidative Stress Mechanisms in the Pathogenesis of Environmental Lung Diseases. In: Chakraborti S, Parinandi NL, Ghosh R, Ganguly NK, Chakraborti T, editors. Oxidative Stress in Lung Diseases. Singapore: Springer Singapore; 2020. p. 103-137. http://link.springer.com/10.1007/978-981-32-9366-3_5.

7. Brandt EB, Myers JMB, Ryan PH, Hershey GKK. Air pollution and allergic diseases. Curr Opin Pediatr 2015;27(6):724-735.

8. Minelli C, Granell R, Newson R, Rose-Zerilli MJ, Torrent M, Ring SM, Holloway JW, Shaheen SO, Henderson JA. Glutathione-S-transferase genes and asthma phenotypes: a Human Genome Epidemiology (HuGE) systematic review and meta-analysis including unpublished data. Int J Epidemiol 2010;39(2):539562.

9. Minelli C, Wei I, Sagoo G, Jarvis D, Shaheen S, Burney P. Interactive Effects of Antioxidant Genes and Air Pollution on Respiratory Function and Airway Disease: A HuGE Review. Am J Epidemiol 2011;173(6):603620. 
10. Huber PC, Almeida WP, Fátima A. Glutationa e enzimas relacionadas: papel biológico e importância em processos patológicos. Química Nova 2008;31(5):1170-1179.

11. Huang H, Nie W, Qian J, Zang Y, Chen J, Lai G, Ye T, Xiu Q. Effects of TNF- $\alpha$ polymorphisms on asthma risk: a systematic review and meta-analysis. J Investig Allergol Clin Immunol 2014;24(6):406-417.

12. Agarwal P, Czarneski JE, Hameed MR. Comparison Study for Identifying Promoter Allelic Polymorphism in Interleukin 10 and Tumor Necrosis Factor\&Genes. Diagn Mol Pathol 2000;9(3):7.

13. Elahi MM, Asotra K, Matata BM, Mastana SS. Tumor necrosis factor alpha-308 gene locus promoter polymorphism: An analysis of association with health and disease. Biochim Biophys Acta

2009 Mar;1792(3):163-72.

14. London SJ, Romieu I. Gene by Environment Interaction in Asthma. Annu Rev Public Health 2009;30(1):55-80.

15. Standardization of Spirometry, 1994 Update. American Thoracic Society. Am J Respir Crit Care Med 1995;152(3):1107-1136. v 2007 Jul 18;(3):CD00621816.

16. Abdel-Rahman SZ, el-Zein RA, Anwar WA, Au WW. A multiplex PCR procedure for polymorphic analysis of GSTM1 and GSTT1 genes in population studies. Cancer Lett 1996;107(2):229-233.

17. Textor J, Hardt J, Knüppel S. DAGitty: A Graphical Tool for Analyzing Causal Diagrams. Epidemiology 2011;22(5):745.

18. Bui DS, Burgess JA, Lowe AJ, Perret JL, Lodge CJ, Bui M, Morrison S, Thompson BR, Thomas PS, Giles GG, et al. Childhood Lung Function Predicts Adult Chronic Obstructive Pulmonary Disease and AsthmaChronic Obstructive Pulmonary Disease Overlap Syndrome. Am J Respir Crit Care Med 2017;196(1):39-46.

19. Owens L, Laing IA, Zhang G, Turner S, Le Souëf PN. Airway function in infancy is linked to airflow measurements and respiratory symptoms from childhood into adulthood. Pediatr Pulmonol 2018;53(8):10821088.

20. Hayes JD, Flanagan JU, Jowsey IR. Glutathione transferases. Annu Rev Pharmacol Toxicol 2005; 45(1):51-88.

21. Watson M. Human glutathione S-transferase P1 polymorphisms: relationship to lung tissue enzyme activity and population frequency distribution. Carcinogenesis 1998;19(2):275-280.

22. Romieu I, Ramirez-Aguilar M, Sienra-Monge JJ, Moreno-Macias H, del Rio-Navarro BE, David G, Marzec J, Hernandez-Avila M, London S. GSTM1 and GSTP1 and respiratory health in asthmatic children exposed to ozone. Eur Respir J 2006;28(5):953-959.

23. Curjuric I, Imboden M, Schindler C, Downs SH, Hersberger M, Liu SLJ, Matyas G, Russi EW, Schwartz J, Thun GA, et al. HMOX1 and GST variants modify attenuation of FEF25-75\% decline due to $\mathrm{PM}_{10}$ reduction. Eur Respir J 2010;35(3):505-514.

24. Reddy P, Naidoo RN, Robins TG, Mentz G, Li H, London SJ, Batterman S. GSTM1 and GSTP1 gene variants and the effect of air pollutants on lung function measures in South African children. Am J Ind Med 2012;55(12):1078-1086.

25. Chen C, Arjomandi M, Tager IB, Holland N, Balmes JR. Effects of antioxidant enzyme polymorphisms on ozone-induced lung function changes. Eur Respir J 2007;30(4):677-683.

26. Lee Y-L, Lin Y-C, Lee Y-C, Wang J-Y, Hsiue T-R, Guo YL. Glutathione S-transferase P1 gene polymorphism and air pollution as interactive risk factors for childhood asthma. Clinical Experimental Allergy 2004 Nov;34(11):1707-13. 
27. Bowatte G, Lodge C, Lowe A, Erbas B, Dennekamp M, Marks G, Perret J, Hui J, Wjst M, Gurrin L, et al. Do Variants in GSTs Modify the Association between Traffic Air Pollution and Asthma in Adolescence? Int J Mol Sci 2016;17(4):485.

28. Gilliland FD, Rappaport EB, Berhane K, Islam T, Dubeau L, Gauderman WJ, McConnell R. Effects of Glutathione S -Transferase P1, M1, and T1 on Acute Respiratory Illness in School Children. Am J Respir Crit Care Med 2002;166(3):346-351.

29. Carroll WD, Lenney W, Jones PW, Strange RC, Child F, Whyte MK, Primhak RA, Fryer AA. Effects of glutathione S-transferase M1, T1 and P1 on lung function in asthmatic families. Clinical Experimental Allergy 2005;35(9):1155-1161.

30. Zhang X, Hirota JA, Yang C, Carlsten C. Effect of GST variants on lung function following diesel exhaust and allergen co-exposure in a controlled human crossover study. Free Radic Biol Med 2016;96:385-391.

31. Hong Y-C, Hwang S-S, Kim JH, Lee K-H, Lee H-J, Lee K-H, Yu S-D, Kim D-S. Metals in Particulate Pollutants Affect Peak Expiratory Flow of Schoolchildren. Environ Health Perspect 2007;115(3):430-434.

32. Zhao Y, Liu S, Liu Z, Ye Y, Mao M. Significant association between GSTT1 null genotype and risk of asthma during childhood in Caucasians. Mol Biol Rep 2013;40(2):1973-1978.

33. Carlsten C, Blomberg A, Pui M, Sandstrom T, Wong SW, Alexis N, Hirota J. Diesel exhaust augments allergen-induced lower airway inflammation in allergic individuals: a controlled human exposure study. Tho$\operatorname{rax} 2016 ; 71(1): 35-44$.

34. Romieu I, Sienra-Monge JJ, Ramırez-Aguilar M, Moreno-Macıas H, Reyes-Ruiz NI, Hernandez-Avila M, London SJ. Genetic polymorphism of GSTM1 and antioxidant supplementation influence lung function in relation to ozone exposure in asthmatic children in Mexico City. Thorax 2004 Jan;59(1):8-10.

35. Chen B-Y, Chen C-H, Chuang Y-C, Kim H, Honda Y, Chiang H-C, Guo YL. Schoolchildren's antioxidation genotypes are susceptible factors for reduced lung function and airway inflammation caused by air pollution. Environ Res 2016;149:145-150.

36. Makamure MT, Reddy P, Chuturgoon A, Naidoo RN, Mentz G, Batterman S, Robins TG. Tumour necrosis factor $\alpha$ polymorphism (TNF-308 $\alpha$ G/A) in association with asthma related phenotypes and air pollutants among children in KwaZulu-Natal. Asian Pacific J Allergy Clin Immunol 2016;34(3):217-222.

37. Yang IA, Holz O, Jörres RA, Magnussen H, Barton SJ, Rodríguez S, Cakebread JA, Holloway JW, Holgate ST. Association of tumor necrosis factor-alpha polymorphisms and ozone-induced change in lung function. Am J Respir Crit Care Med 2005;171(2):171-176.

38. Li Y-F, Gauderman WJ, Avol E, Dubeau L, Gilliland FD. Associations of Tumor Necrosis Factor G-308A with Childhood Asthma and Wheezing. Am J Respir Crit Care Med 2006;173(9):970-976.

39. Melén E, Nyberg F, Lindgren CM, Berglind N, Zucchelli M, Nordling E, Hallberg J, Svartengren M, Morgenstern R, Kere J, et al. Interactions between Glutathione S- Transferase P1, Tumor Necrosis Factor, and Traffic-Related Air Pollution for Development of Childhood Allergic Disease. Environ Health Perspect 2008;116(8):1077-1084.

40. VanderWeele TJ. On the Distinction Between Interaction and Effect Modification. Epidemiology $2009 ; 20(6): 863-871$.

\section{Hosted file}

FIGURE_1_DAGs.docx available at https://authorea.com/users/424884/articles/529883effect-modification-by-gst-and-tnf-\%CE\%B1-polymorphisms-in-the-association-betweenair-pollution-and-lung-function-in-asthmatic-children

\section{Hosted file}


FIGURE_2_Flow_diagram.docx available at https://authorea.com/users/424884/articles/529883effect-modification-by-gst-and-tnf-\%CE\%B1-polymorphisms-in-the-association-between-airpollution-and-lung-function-in-asthmatic-children

\section{Hosted file}

TABLE 1 Study population.docx available at https://authorea.com/users/424884/articles/529883effect-modification-by-gst-and-tnf-\%CE\%B1-polymorphisms-in-the-association-between-airpollution-and-lung-function-in-asthmatic-children

GSTM1

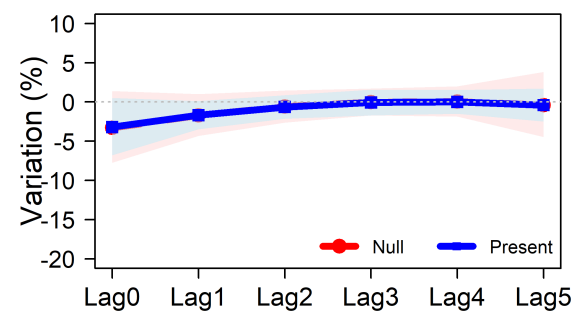

GSTT1

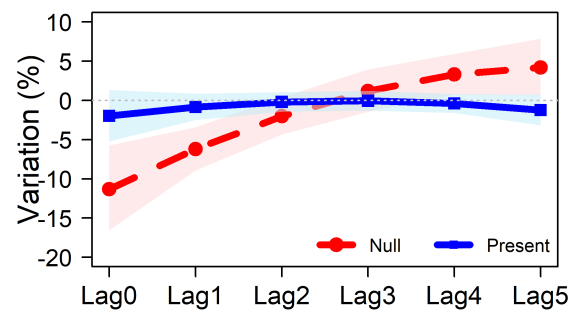

GSTP1

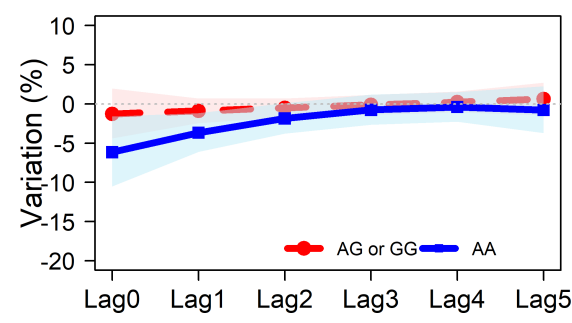

TNF-308

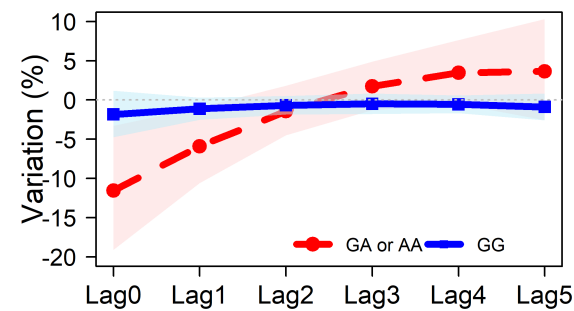

TNF-1031

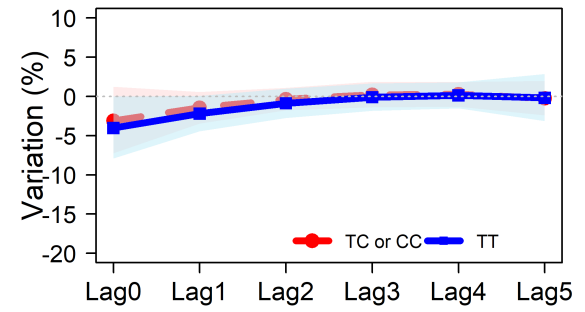



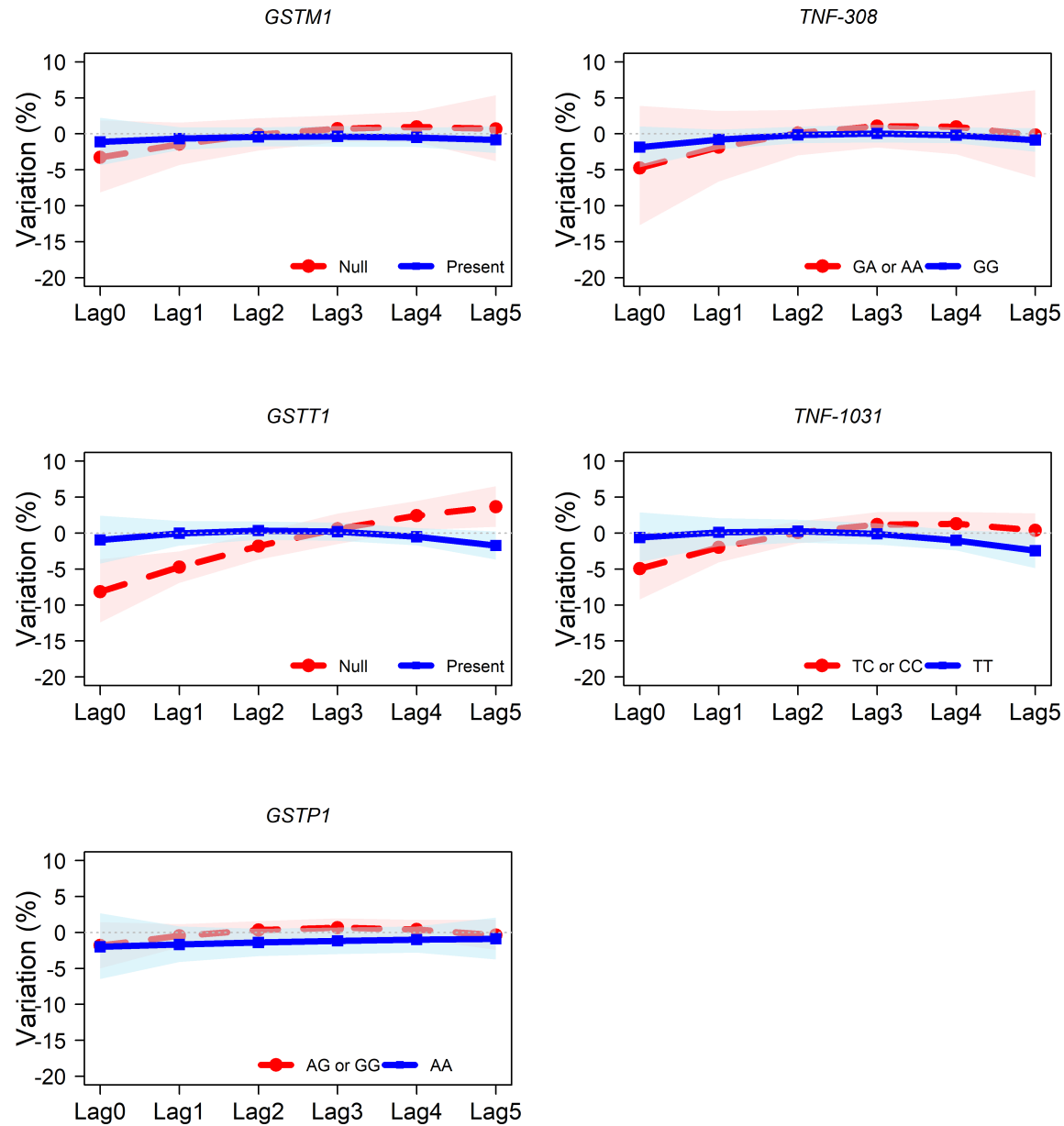
GSTM1

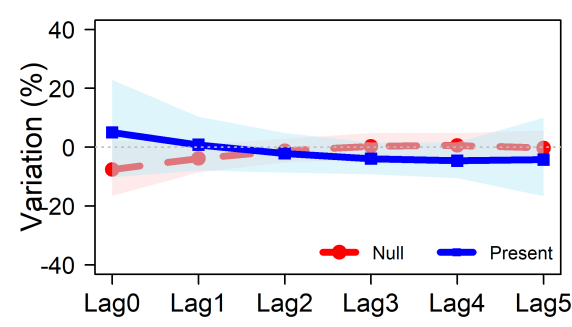

GSTT1

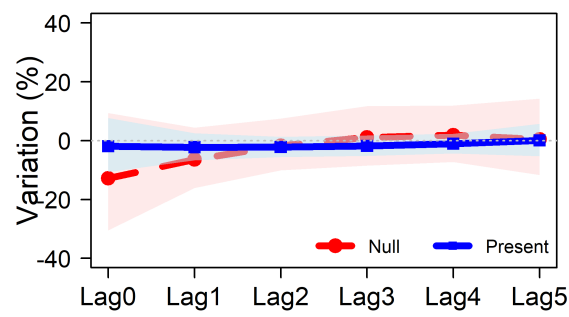

GSTP1

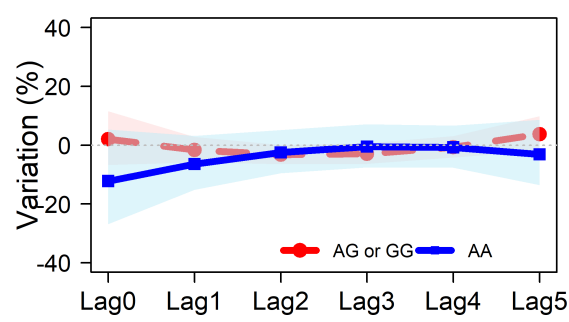

TNF-308

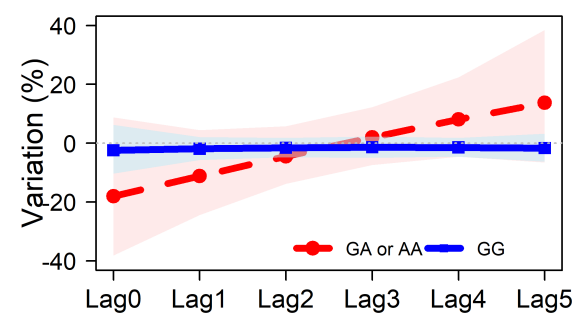

TNF-1031

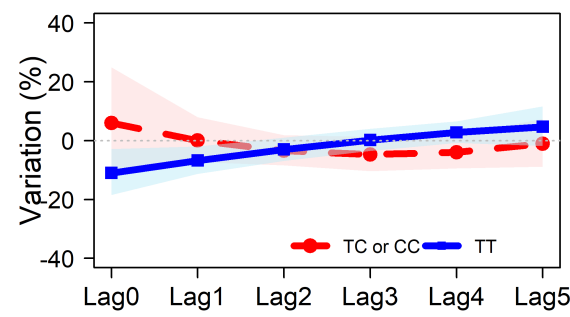

\section{Hosted file}

Image Legends.docx available at https://authorea.com/users/424884/articles/529883-effectmodification-by-gst-and-tnf-\%CE\%B1-polymorphisms-in-the-association-between-airpollution-and-lung-function-in-asthmatic-children 